\title{
LA UNIDAD FALTANTE, ESPECIFICIDAD Y ROL DE LAS HUMANIDADES
}

\author{
Eduardo Carrasco P. \\ Depto. Filosofía, Facultad de Filosofía y Humanidades, Universidad de Chile
}

"Solo sé que nada sé" (Sócrates)

\section{ANTECEDENTES QUE DEBEN TENERSE EN CUENTA}

En el último tiempo han surgido cuestionamientos frente a la forma de las publicaciones que han venido adoptando las humanidades. Esta forma de discurso tiene su origen en la exigencia puesta por las instituciones que otorgan fondos para la investigación, las cuales buscan homogeneizar el trabajo intelectual estableciendo como pauta el tipo de escritos propios de las ciencias positivas. Además de ello, las propias instituciones universitarias se han visto obligadas a establecer sus criterios de evaluación y de calificación acomodando sus exigencias a este modo de exposición del trabajo intelectual. Así, el llamado "paper" se ha ido imponiendo como única forma válida de publicación en las humanidades. Este fenómeno tiene directamente que ver con las transformaciones que han tenido lugar en la historia de la enseñanza superior en los últimos decenios, en la cual las ciencias positivas y la formación profesional han pasado a ocupar un lugar central en estas instituciones, imponiendo sus modalidades de acción y estableciendo un ordenamiento cuyas implicancias epistemológicas están hoy día lejos de ser aclaradas. El "paper" es solo una de las expresiones de este fenómeno más amplio, que tiene que ver con el predominio de los criterios pragmatistas en la enseñanza superior y que busca configurar el cuerpo entero del saber sobre bases técnicocientíficas, imponiendo como única forma de rigor el propio de las ciencias 
positivas y de la técnica ingenieril. De ahí que si queremos comprender la situación actual y el menoscabo de las humanidades, estamos obligados a repensar este asunto desde el fondo y a determinar su especificidad frente a los modos propios de la ciencia y de la técnica. Si lográramos cumplir con este propósito, podríamos mostrar que no solo los modos de escritura de las humanidades "remedan" inútilmente las modalidades de comunicación propias de la ciencia, sino que, además, la imposición de estas exigencias propende a la desarticulación del saber y corroe el sentido esencial de la institución universitaria.

\section{EL PARADIGMA DEL SABER COMPLETO}

Aunque la época moderna haya logrado grandes progresos en el avance hacia una comprensión y organización del saber, podemos afirmar que todavía operan en la estructura organizativa de nuestras instituciones de enseñanza los criterios nacidos de un antiguo paradigma que en cierto modo altera y desfigura su naturaleza. Este paradigma aún activo, que tiene sus raíces en el origen mismo de las universidades en la Edad Media, parte de algunos supuestos que aunque el ejercicio de nuestra enseñanza parece haber abandonado, debido a la escasa reflexión sobre estos temas en nuestro medio, ellos siguen involuntariamente vigentes en nuestras instituciones del saber, cuestión que dificulta llevar a la práctica todas las consecuencias de la nueva situación epistemológica.

El paradigma en cuestión se funda en el supuesto de que el conocimiento, en sus distintas ramas, puede constituirse como un corpus de enseñanzas completo y sistemático, del que podríamos disponer y transmitir de generación en generación, como si se tratara de un todo realizado, el cual, si bien no se considera permanente, al menos pareciera concebirse como muy durable a través del tiempo. Para este concepto del saber, lo decisivo estaría en las respuestas, hasta el punto de considerar los cuestionamientos, las preguntas, o las dudas, con una cierta desconfianza. "Saber" sería aquello que se consolida y deja atrás las preguntas, las que aparecen como momentos que podrían tener importancia como factores desencadenantes del proceso, pero que son abandonados una vez que se pasa al mundo del conocimiento. El saber -especialmente el saber que se enseña- sería solo el saber del saber, y en ningún caso el saber del no saber. 
Este supuesto nace de la idea religiosa, según la cual la verdad le habría sido revelada al ser humano en su totalidad y que, por tanto, el principal problema que ella presenta sería su preservación, su administración y su puesta a salvo de herejías y malas interpretaciones. Es sobre la base de esta idea que se constituyeron en un comienzo las universidades, las cuales por eso intentaron ordenar el conocimiento como un todo fijo y logrado. De esta idea proviene además la estructuración de estas instituciones en facultades y la tendencia a constituir corpus de conocimientos estables e independientes.

No es un hecho menor el que las universidades sean, junto a la Iglesia, una de las instituciones más antiguas, y ambas, sin duda, las únicas que durante siglos han perdurado a lo largo de la historia. Debido a que en los comienzos de la Edad Media el saber y la educación se encontraban relegados a las escuelas existentes en los monasterios y catedrales (Bolonia, París, Salerno, San Millán, Córdoba, etc.), la estructuración de estas instituciones se hizo conforme al modelo eclesiástico. Algunas de estas escuelas alcanzaron el grado de Studium Generale porque recibían alumnos de fuera de sus diócesis y concedían títulos que tenían validez fuera de ellas; contaban con estatutos y privilegios otorgados primero por el poder civil y posteriormente ampliados por el papado, pero en lo que concernía al contenido y a la organización de sus estudios, eran observadas de cerca por las instancias eclesiásticas, con el objeto de que no se propagaran herejías o desviaciones de la ortodoxia. Al principio, las universidades eran exclusivamente centros de enseñanza de la filosofía escolástica y de las humanidades. Poco después, se integraron las ciencias, las ciencias aplicadas y otras. A medida que se fueron introduciendo estas diferentes disciplinas, comenzaron a nacer separaciones internas, articulándose la estructura universitaria de acuerdo a criterios diferentes. Este crecimiento por agregación de disciplinas es lo que explica que en la actualidad la diferenciación en facultades no responda a un principio común, pues en algunos casos se trata de unidades de enseñanza de disciplinas aplicadas, separadas de acuerdo a su diferente finalidad práctica (como, por ejemplo, medicina, dentística, arquitectura, etc.), y en otros casos, en cambio, se trata de diferenciaciones en función del objeto de estudio, como ciencias, filosofía y humanidades, ciencias sociales, etc. 


\section{EL MODELO DE LAS CIENCIAS POSITIVAS}

A partir del prototipo de saber que la modernidad desarrolló siguiendo el modelo de la física, las ciencias positivas lograron constituirse en sistemas de conocimientos que a su manera le dieron continuidad al paradigma escolástico. Aunque quedaron atrás las fundaciones religiosas, gracias a las nuevas formas de fundamentación en principios racionales, autónomos, y libres de la fe y la creencia, las ciencias, siguiendo el modelo de la física, lograron constituirse en corpus de conocimientos compartidos por los especialistas y corroborados por la experimentación. Estas unidades pudieron ser recogidas en textos que pueden diferir en cuanto a las modalidades de exposición, pero no en cuanto al contenido, siendo éste el resultado de un esfuerzo de la comunidad científica a nivel mundial. Los conceptos de "teoría", "hipótesis", "corroboración experimental" y otros, pasaron a modificar completamente, tanto las formas de obtención de conocimientos, como sus modalidades de exposición y de transmisión. Sin embargo, el carácter de las ciencias mantuvo la forma de un cuerpo de conocimientos positivos y unitarios con resultados compartidos. El paso desde las ciencias puras hacia su aplicación reforzó la idea pragmática que privilegió el puro saber frente al saber del no saber y generó la actual situación en la cual todo intenta ordenarse todavía bajo la forma de una positividad lograda, siendo precisamente esta ilusión la que explica la aplicación de un mismo patrón de procedimientos a todas las disciplinas del saber.

Debido a que las disciplinas humanistas, y particularmente la filosofía, no pudieron constituirse según este modelo - precisamente porque para ellas la apertura hacia un permanente cuestionamiento y el carácter individual de sus resultados forman parte de su orientación esencial- en los círculos del conocimiento comenzaron a observarse con cierta desconfianza y a cuestionarse en su misma validez, llegando en posiciones extremas a negar su viabilidad o su legitimidad. El hecho de que estas disciplinas aparecieran marcadas por un inútil pero constante proceso de conformación, pero no como sistemas unitarios de conocimientos, las hizo ver como una mera aspiración a un saber que nunca se realizaría. En realidad, lo que de esa manera ingenua se descubría era lo que siempre constituyó su esencia, definida desde un comienzo precisamente como eso mismo que ahora aparecía, como un amor al saber, pero nunca como un saber realizado y perfecto que los antiguos solo le atribuían a sus dioses. 
Por este motivo, lo que comenzó a suceder cada vez con mayor fuerza es la clara separación entre la práctica de la enseñanza y la investigación en las ciencias positivas, y el ejercicio de la enseñanza y la creación en el ámbito de las humanidades, aunque estas últimas nunca hayan sido verdaderamente capaces de hacer comprender cabalmente su propia forma de conocimiento y legitimarla. En la actualidad, las modalidades científicas han adquirido un carácter de modelo, imponiendo sus procedimientos y pasando a dirigir los procesos e instituciones del saber. Esta situación ha ido en menoscabo de las humanidades y en cierto modo ha generado una incomprensión mayor de la que se habría podido esperar, pues, por razones prácticas, éstas, en lugar de intentar consolidarse a partir de sus propias especificidades, se han inclinado ante los criterios impuestos por la ciencia, aun a riesgo de desnaturalizar su propia esencia.

Esta situación, desde ya bastante crítica, se ha complicado aún más debido a las circunstancias histórico políticas que han conducido a la mayoría de los países hacia un sistema económico en el que el pragmatismo parece ser la única ley.

\section{EL CASO DE CHILE}

El actual movimiento de transformaciones que viven las universidades públicas en Chile debe ubicarse en el marco más amplio del proceso llamado de "modernización" del país, que siguió un cierto camino hasta septiembre de 1973 y que posteriormente fue encauzado por la dictadura militar en un sentido diferente, dirección cuyas consecuencias positivas y negativas estamos viviendo hoy día. Dicho movimiento, en lo que se refiere a los intereses de la cultura y de las humanidades, puede caracterizarse como un proceso de modernidad unilateral, en el cual se han instaurado las bases económicas, legales y administrativas para el funcionamiento de un sistema neoliberal, pero sin que se hayan edificado los cimientos de un desarrollo cultural paralelo que sustente lo que no puede afirmarse por razones del mercado. Esta unilateralidad es connatural a la ideología neoliberal, para la cual lo que no es directamente solicitado por la demanda no tiene muchas razones de ser y debe abandonarse a su propia suerte. Junto con ello, dentro de esta idea de sociedad, el Estado debe reducir su influencia para permitir que sea la propia iniciativa privada la que responda a la mayor parte de las necesidades sociales. La expansión de esta idea al plano educativo ha dado lugar a la 
creación de universidades privadas y ha afectado gravemente la situación de las universidades estatales. Así, en este sistema neoliberal, las humanidades y la cultura han quedado simplemente relegadas a ser y a hacer lo que permita la demanda de una sociedad que, por otra parte, es condicionada por el mismo mercado para dirigirse hacia valores y formas de consumo masivo, ajenos, y hasta en cierto modo, hostiles, a los propósitos de estas disciplinas. La filosofía y las humanidades, en su legalidad interna de desarrollo, no responden a la lógica propia de existencia de la técnica, ni tampoco a la lógica de desarrollo positivo de las ciencias. La técnica es la expresión más clara de una transformación de la práctica que viene instaurándose en el mundo desde los comienzos de la época moderna y de la cual forman parte las dos modalidades más relevantes de los avances actuales, la revolución de las comunicaciones y, al interior de ella, la revolución informática. Estas formas de ordenamiento de la acción en las sociedades contemporáneas tienen un alto grado de autonomía en su desarrollo, aunque son funcionales al sistema económico operante en la sociedad. Cada avance técnico se transforma de inmediato en una nueva fuente de ofertas en el mercado y, a la inversa, la constante multiplicación de la demanda exige una respuesta técnica inmediata, que viene a constituirse en un nuevo factor de su expansión.

La ciencia, por su parte, también responde a modalidades de existencia y de desarrollo propias, que aunque en general se entrelazan con las de la técnica, no necesariamente ni en todo dependen de ella. Su entrelazamiento hace que también la realidad de la ciencia tienda a ser funcional con el desarrollo económico neoliberal. Esto ocurre de manera clara en las sociedades desarrolladas, en las que incluso la investigación llega a transformarse en un producto que se vende y se cotiza en el mercado. En EE.UU., Inglaterra o Francia, por ejemplo, existen empresas de investigación que venden sus servicios directamente al Estado o a las empresas productivas. La realidad nuestra es diferente, pues la empresa privada en Chile, e incluso las empresas del Estado, en su gran mayoría trabajan con tecnologías importadas, lo cual explica el grado de relativo abandono en que se encuentra el desarrollo científico nacional. Es importante observar sin embargo que esta situación de postergación no se debe a exigencias que broten de las propias particularidades del trabajo científico -como es el caso de las humanidades- sino más bien a la relación de dependencia recién citada. La aplicación del criterio de reducir las acciones al menor costo posible genera la situación de dependencia tecnológica y científica, pues dado que somos un país subdesarrollado, al aplicar los criterios neoliberales en estos ámbitos, se prefiere importar los productos de 
la inteligencia ajena a gastar recursos en desarrollar la inteligencia propia. Esto hace que, aunque por razones diferentes, en nuestro país tanto la ciencia como las humanidades estén en una situación de menoscabo con respecto a las áreas de formación profesional, las que por las mismas razones pragmáticas reciben una atención preferencial en todas las etapas de la enseñanza.

En las universidades estatales, conmocionadas por los avatares de esta modernización unilateral, encontramos las tres disciplinas anteriormente citadas: la formación e investigación en disciplinas eminentemente técnicas, que tienen que ver con la finalidad profesional de ciertas enseñanzas, la formación e investigación en las ciencias y la formación e investigación en las humanidades. Desde su fundación, y siguiendo una tradición que proviene del origen mismo de las universidades, fueron las humanidades quienes aseguraron la integración y la unidad de las primeras instituciones. Pero a partir del nuevo proceso de modernización, ellas fueron desplazadas, sin que la ciencia ni la técnica hayan podido salvaguardar verdaderamente la unidad del saber. Esto ha generado una situación de crisis del concepto mismo de universidad, que se ve desprovisto de lo que desde un comienzo caracterizó su misión, esto es, el universalismo y la totalización del saber. Las humanidades, que fueron la cabeza de estas instituciones hasta mediados del siglo pasado, han sufrido un proceso de deflagración que nos lleva a la actual situación de crisis y de deterioro. Obligadas a inclinarse a criterios cada vez más tecnocráticos y pragmáticos, ellas se fueron transformando en los parientes pobres de estos procesos en los que en verdad poco tenían que aportar.

\section{ESPECIFICIDAD DE LAS HUMANIDADES}

A diferencia de la técnica y de la ciencia, que en sus modalidades actuales tienen su origen en la época moderna, las humanidades nacen en la antigüedad y han atravesado épocas y siglos diferentes, sin que hayan cambiado sus rasgos esenciales. La historia, la literatura y la filosofía antigua no han perdido su vitalidad con el paso del tiempo. Se sigue leyendo a Sófocles, a Heródoto, o a Platón, con la misma pasión con la que fueron leídos en su tiempo, y tiene tan poco sentido decir que Shakespeare sea un avance con respecto a Eurípides, como decir que Kant supere a Sócrates, o Braudel a Tucídides. El tiempo de las humanidades es otro y su relación con el tiempo es también otra. Se trata en ellas de una historia que no pierde vigencia con 
el tiempo, sino, al contrario, adquiere el carácter de un mensaje permanente que es fundamental conocer si se desea prolongar su legado.

De ahí que las humanidades se asienten en la tradición de ellas mismas, que traslada a través de los siglos los valores que hicieron en un momento dado, del bárbaro un hombre verdadero, capaz de comprenderse a sí mismo, de comprender a los demás, de abordar los grandes enigmas, de emprender las aventuras de la creación y la imaginación. No son ellas fanáticas del progreso y todas miran con un cierto escepticismo las utopías que prometen cada vez comenzar de nuevo, para encontrar la felicidad en un recodo todavía no transitado de los tiempos. Son más bien respetuosas y amantes del pasado y si miran hacia adelante, intentan hacerlo con la sabiduría del que sabe que en la historia humana son más las cosas que se repiten, que las cosas que verdaderamente se renuevan. La modernidad no las entusiasma, al menos en el modo como la presenta la sociedad de consumo neoliberal. Ponen el acento en aspectos más profundos, menos perecederos, menos ostensibles, no confían en los fuegos artificiales de la política contingente, ni en las estadísticas, ni en la publicidad, ni en la prosperidad de los supermercados, ni en los nacionalismos fáciles.

Sus cultores buscan más darle curso a una vocación, que ganarse la vida con una profesión. Si hicieran cálculos al decidir seguir este camino, lo más probable es que se hubieran apartado de él, entrando en los negocios, en los beneficios de una profesión liberal, haciendo política o intentado una carrera militar, que en los últimos tiempos ha dado buenos dividendos. Esta característica es muy importante para comprender por qué sus cultores han aceptado una situación tan precaria en relación con sus salarios y ganancias: la actividad que realizan, por responder a una vocación ineludible, no descansa en el interés pecuniario y seguiría siendo realizada aun en el caso de que no reportara dinero. La fuerza de esta vocación ha sido una de las causas por las cuales los profesores de las disciplinas humanistas han tenido una gran capacidad de soportar sin rebelarse el régimen de menoscabo económico que actualmente impera en estas áreas en las universidades públicas.

Sus maneras de hacer y, por tanto, de ser, también son otras. Ellas dependen fundamentalmente de potencias creadoras individuales, más que de ese trabajo de hormigas que caracteriza el trabajo científico. No hay en las humanidades investigaciones de punta que tengan que ser defendidas de la competencia, y no existen avances que vayan a ser medidos por disminuciones de costos, mayor productividad o aplicaciones mediatas o inmediatas. Ciertas obras sientan un precedente que jamás será rebasado, transformándose en hitos 
fundamentales de nuestro desarrollo. Nada de lo grande queda definitivamente desterrado, pues se transforma en tradición, en punto de partida interminable para nuevas reflexiones. No se da nada por definitivamente despachado, todo sigue en discusión, el gran misterio es el fuerte que las atrae y que desean embestir, y cuyas puertas siguen abiertas antes y después de sus asaltos.

Las humanidades tampoco requieren de la unanimidad. Prefieren la dispersión, la multiplicidad, la constante revisión de lo ya afirmado. Viven de la libertad más que de las ataduras a sistemas o a ideologías. Sus cultores no podrían trabajar a gusto bajo la tutela de instituciones que estrechen los marcos de su reflexión. Quieren estar sometidas a las solas exigencias que surjan de la fidelidad a su trabajo, y ése quieren hacerlo bien, con seriedad y con profundidad, porque saben que de otra manera este pierde todo sentido. Su rigor no es la exactitud, no son capaces de reducir lo que hacen a términos matemáticos, y si alguna vez lo intentan, quedan cabos sueltos, o nudos que no se pueden desamarrar. Su rigor está en la fidelidad a las fuentes, en la exigencia de claridad unida a la creatividad, en la discusión con lo ya logrado o con aquello que despierta la discusión contemporánea.

Sus cultores trabajan con profundas convicciones y con la confianza de que si se los ignora, incluso si quien lo hace es una ciudad, un país o una época, pierde lo más hondo de la vida, porque confían en la acción invisible del pensamiento y porque saben que en las humanidades se deciden cosas tan importantes para el ser humano como su identidad, el significado de su mundo, la lengua que nombra todas sus cosas, su memoria, todas realizaciones en las que late el futuro con mucha mayor fuerza de la que es capaz de darle el cálculo económico, la utopía política o el sueño de la técnica. Las épocas en las que se ha apagado su luz, la luz del pensamiento, son las más terribles, las más desesperanzadas, las más crueles.

Estas características son difíciles de comprender en una época en que lo que predomina es la preocupación por los resultados inmediatos, la atención a la contingencia, el éxito publicitario, las simplezas de lo cuantitativo, la eficacia a toda prueba, lo contante y sonante. Por eso, toda esta situación de crisis y de incomprensión de este quehacer se traduce en distorsiones con respecto a él, que en lo práctico finalmente inciden en dos órdenes de cosas: en primer lugar, en la no existencia de una política diferenciada en el terreno académico, que respete la especificidad del trabajo de las humanidades y de sus propias modalidades de desarrollo en evaluaciones y calificaciones. En segundo lugar, en la no existencia de una política económica diferenciada, que asuma derechamente que estas disciplinas no son autofinanciables y 
que no tienen demanda de mercado que pueda permitir su financiamiento por vías privadas. El Estado debe financiarlas, porque son ellas el lugar privilegiado de desarrollo del pensamiento libre, factor fundamental de la unidad de la nación. Con cualquier financiamiento privado se corre el riesgo de desnaturalizar su vocación libertaria y liberal, que busca con los medios propios del conocimiento humano dar respuesta siempre provisoria a los enigmas propios de su existencia.

\section{LAICIDAD Y SENTIDO UNIVERSAL DE LA UNIVERSIDAD}

El término "laicidad" remite a la palabra griega "laos", que significa la unidad de una población, aquello que es común para todos sus componentes. Laicidad significa que ninguna creencia o ideología debe gozar de ventajas que puedan conducir a una discriminación. La laicidad es la afirmación positiva de que aspectos fundamentales de nuestra vida pueden ser abordados más allá de nuestras divisiones o separaciones políticas, ideológicas o religiosas. En definitiva, ser laico significa afirmar que lo que compete a nuestra vida en común debe ser abordado desde principios que nos unen a todos, poniendo entre paréntesis aquellos que nos separan, es afirmar que el espacio público es un terreno de neutralidad que debe representar legítimamente a todos los ciudadanos. Por lo tanto, la laicidad es el pensamiento republicano, que busca legislar y tomar decisiones de Estado desde lo que nos es común, sin pretender obligar a otros a someterse al dictado de nuestras propias preferencias. Ser laico es respetar el derecho de ser minoría y aprender a ubicarse en un terreno donde todos podemos estar de acuerdo. Las humanidades, tal como han sido desarrolladas en la Universidad de Chile, representan precisamente este espíritu republicano, sin el cual no solo es la Universidad la que hace agua, sino el país en su conjunto. Abrirle espacios a la diversidad sin desarrollar el espíritu común, tal como se ha hecho durante todos estos años, fomentando las iniciativas privadas en el terreno de la educación superior sin potenciar a las universidades públicas, es una política altamente peligrosa, que en los hechos antepone los intereses que pueden algún día ser generadores de conflicto, al reforzamiento del terreno común en el que todos los chilenos debemos entendernos. El rol de las diferentes universidades estatales todavía existentes es fundamental para garantizar el desarrollo de este espíritu ciudadano y para construir un país unido y no un país de sectas. Las humanidades han 
sido, siguen y seguirán siendo las fuerzas fundamentales para garantizar la existencia y la consolidación de este espacio.

¿Cómo puede llegar a tener sentido la existencia unificada de disciplinas tan diferentes en el seno de una misma institución como es la universidad? ¿Cómo pueden coexistir las ciencias y las disciplinas humanistas sin que haya trasposición de los criterios de unas a otras? ¿Qué es una universidad? ¿Por qué las humanidades tienen que desarrollarse en el marco de una universidad pública? Estas son las preguntas que debemos intentar responder, para poder llevar a cabo medidas que no distorsionen la misión de la universidad y ubiquen a las humanidades correctamente dentro del sistema del saber institucional.

Nuestra respuesta es simple: una universidad es una universidad. Esto es, no es un instituto de formación profesional, no es un instituto de investigación científica, no es un centro educativo en disciplinas variadas. Estas tres actividades pueden existir en instancias que no sean una universidad. Pero ellas pueden existir también en una universidad, aunque ninguna de ellas por separado, ni tampoco su suma, constituyen el ser universidad de la universidad.

¿Qué es entonces una universidad? Universidad es la reunión en una unidad de todas las disciplinas que existen en su seno -ciencias, filosofía y humanidades, artes y creación, enseñanza ligada a cada una de estas disciplinas, formación profesional y técnica-, unidad en la que se preserva la universalidad del saber. Pero, insistimos, la unidad no es la simple coexistencia de todas ellas. Solo hay unidad allí donde la coexistencia responde a una fuerza unitaria. En el pasado, como lo hemos dicho, la fuerza unitaria estaba constituida por la unidad teológica del saber. Por eso, el origen de la universidad está directamente vinculado con la filosofía escolástica, es decir, escolar: se dispone de un saber unitario que puede ser enseñado como un conjunto (Summa), una doctrina. Con posterioridad a la Edad Media, esta unidad se fue disolviendo, ocupando la filosofía un lugar cada vez más preponderante. Ésta, bajo diferentes intentos, trató de reemplazar a la unidad religiosa sin lograrlo. La modernidad terminó por deshacer completamente este esquema y condujo a un desarrollo cada vez más independiente del antiguo centro unitario. Finalmente, fueron las ciencias las que desplazaron a la filosofía y se ubicaron en el centro indiscutido del saber. Pero lo peligroso de este traspaso fue que con él vino la pretensión de la ciencia de asentarse como saber positivo desde el cual toda otra disciplina debía normarse. A partir de eso, solo lo que fuera ciencia y lo que respondiese a sus criterios y a sus modalidades de discurso tendría legitimidad como conocimiento. 


\section{LA UNIDAD FALTANTE Y LA UNIVERSIDAD ACTUAL}

En la actualidad, a pesar de su situación privilegiada para instalarse como centro, las ciencias positivas se han organizado con criterios de autonomía; lo mismo ha ocurrido en la formación profesional y en la enseñanza técnica, que también han adquirido un carácter independiente. La centralidad ha desaparecido, y eso ha derivado hacia un estado de cosas en el cual la ciencia, la formación profesional, la creación y las humanidades coexisten sin que aparezca la fuerza que pudiera darles unidad. Esto es la desintegración de la universidad. La universidad deja de ser universidad, pasa a ser muchas cosas diferentes juntas, administradas desde un centro que no es más que centro administrativo. Lo que queda hoy día de universidad en la Universidad de Chile, por ejemplo, es la Casa Central. Al mismo tiempo, aparecen las "universidades" privadas, que son centros administrativos de funciones diversas, formación profesional, enseñanza de disciplinas científicas y técnicas diversas, enseñanza de las humanidades, etc. Es decir, la palabra "universidad" ha comenzado a perder toda significación y puede dar a entender cualquier cosa, predominando ahora en su concepto la formación profesional.

¿Pero en este proceso desintegrador del saber y de su enseñanza, que responde a las fuerzas esenciales de la modernidad, podemos dar por desaparecida definitivamente la universalidad de la universidad? ¿O se trata de un estado provisorio? Una vez que ha quedado oculta la universalidad como centro unitario, ¿subsiste como realidad oculta, o su desaparición significa una verdadera aniquilación? La universalidad de una doctrina o de un saber determinado no es ya más fuerza unitaria; eso es un hecho, ¿Pero existe una fuerza unitaria oculta o supuesta, incluso en la desintegración de la universidad? ¿Responde la desintegración de la universidad a una retirada de la unidad para hacerse sentir como unidad que falta? ¿No será tal vez precisamente la falta de unidad la que ahora toma el rostro de la unidad? ¿La falta de unidad es un fenómeno negativo, o hay una positividad en la propia falta que nos permita reconstituir la universidad a partir de ella?

Nos atrevemos a afirmar que hoy día la universidad se presenta como la unidad faltante que reúne a las ciencias, a las humanidades, a la creación y a la formación profesional. La universidad es lo que está por reconstruirse. Solo hay universidad allí donde se plantea la exigencia de reconstruir la unidad faltante. La universidad se transforma en una dirección hacia la unidad, más que en una unidad real actuante. Pero esta unidad faltante, que es la apertura hacia un saber que no se tiene, pero que se busca, no pierde por ello un poder de integración. Este continúa allí donde se actúa con la 
conciencia y la responsabilidad frente a esa unidad que falta. La unidad ahora es la dirección del proceso, unidad tal vez nunca alcanzada como realidad final y acabada, pero siempre presente como unidad avizorada, requerida, buscada. Así, las unidades obtenidas en las épocas del pasado por la teología y por la filosofía (ciencia), que aparecían como formas reales y logradas de universalidad, se muestran ahora como diferentes maneras de suplantación de la unidad faltante, que siempre ha estado allí, brillando por su ausencia, pero sin ser reconocida como tal. Esto es, al parecer, lo que prolonga la historia de la universidad hacia un tiempo que va más allá de la modernidad.

La unidad se hace presente en la formación profesional en la medida en que se reconoce en su interior la necesidad de su complementación con las disciplinas creativas. No existe verdadera formación en una ciencia, si no hay al mismo tiempo creación de nueva ciencia. La ciencia nunca es algo hecho de una vez y para siempre, sino siempre algo por hacerse. Este "por hacerse" remite claramente a una unidad faltante. De ahí que lo creativo sea lo más universitario. Pero, además, el movimiento de las ciencias hacia la especialización puede todavía reconocer el desvarío que conlleva la particularización sin integración. Si bien en el estado actual del desarrollo de las ciencias las especialidades pueden seguir desarrollándose sin necesidad de remitirse a otras disciplinas no científicas, en el límite de las ciencias siempre vuelve a aparecer la exigencia de una integración abierta a campos muy ajenos a la ciencia (filosofía y hasta religión). No existe tampoco un verdadero pensamiento creador (filosofía y humanidades), si no hay un constante diálogo con la ciencia. No existe verdadera ciencia, ni verdadera formación profesional, ni verdadera filosofía, si estas no están dirigidas hacia la configuración de mundo. Por todas partes, la identidad nacional, la cultura, el arraigo, la sociedad constantemente a la búsqueda de sí misma, remiten a la unidad faltante, a un horizonte avizorado, pues ninguna de estas instancias puede considerarse como un dato, como algo ya hecho, como mero punto de partida. Así, las actividades de la universidad, en la medida en que se orientan hacia una unidad que falta, no solo responden a exigencias internas, propias de la vida universitaria, sino a necesidades mucho más generales, que alcanzan incluso hasta la vida del conjunto de la nación en casi todos sus aspectos.

La frase, "la universidad es una universidad" quiere entonces decir que lo propio de la universidad reside en la unidad faltante. Todas las instituciones de educación superior que no enfrenten el problema de la unidad faltante en forma global, y abordando también cada uno de los aspectos que derivan de su búsqueda, no son universidades. Y esta unidad faltante, que pudiera 
desconcertar por lo paradójico de su presencia ausente, tiene su correlato exacto en el carácter actual de apertura de las ciencias y de todas las disciplinas del conocimiento. Ayer formaron parte de un todo que se suponía alcanzable o ya logrado, y hoy siguen interconectadas, sin que por ello deba suponerse un todo real del saber como positivamente existente. Toda ciencia hoy día debe asumirse a sí misma como un conocimiento abierto al conocimiento, ocupando esta misma apertura un papel determinante en su propia definición. El hecho de que cada una de las ciencias se mantenga abierta a la espera de nuevas aventuras del conocimiento no atenta en absoluto en contra de su unidad como ciencia. En el mismo sentido, la unidad faltante del conjunto de los saberes y sus enseñanzas, lejos de ser una idea abstracta e inasible, constituye la fuerza integradora de la universidad. Esto hace que sea característico de la universidad en la época de la unidad faltante, la necesidad del reconocimiento de la multidisciplinariedad, de la inter-disciplinariedad y de la intra-disciplinariedad, como rasgos esenciales hacia los cuales debe apuntar el desarrollo de cada una de las disciplinas al interior de la universidad.

\section{EXIGENCIAS QUE VIENEN DE LA UNIDAD FALTANTE}

La unidad faltante exige además de la universidad la disposición a abordar el problema del saber sin ningún tipo de prejuicio desde el cual se pretenda reconstruir la unidad como realidad. La verdadera unidad de la universidad viene de la búsqueda de la unidad siempre faltante. Por ello, el laicismo, entendido en el sentido más amplio posible, es decir, como total apertura hacia cualquier eventual camino del conocimiento, sin trabas ideológicas, políticas, religiosas o de otro tipo, es la condición sine qua non que pone la esencia misma de la universidad para existir como tal. El laicismo no es el simple respeto a las diferentes opiniones, sino el modo propio como enfrenta la universidad la falta de unidad desde la cual ella surge como institución del saber. Exige a su vez el respeto a las diferencias, pero el laicismo no es una actitud personal e individual que se requiera de los académicos y estudiantes, sino la condición de existencia del desarrollo de la institución hacia la unidad faltante. La unidad faltante no es algo que precisamente por faltar no tenga ninguna incidencia en la vida de la universidad. La unidad faltante es el terreno de origen de una universidad pública. Una universidad confesional no puede constituirse plenamente como una institución que responda cabalmente a la exigencia esencial actual de lo universitario, precisamente 
porque ella tiene una unidad real proveniente de su credo. De ahí que solo una universidad estatal pueda responder a las altas exigencias puestas por la unidad faltante, alcanzando la laicidad y el pluralismo requerido por el saber. Lo que actualmente no existe en Chile es la conciencia de que no todo es ideológico, teórico, político, religioso, etc., es decir, la conciencia del poder congregador de la unidad faltante.

La modernidad neoliberal, en el terreno del conocimiento y de su enseñanza, tiende a acentuar la disgregación hasta su extremo posible. Ello hace que lo universitario se pierda, transformándose todo centro de formación superior en un centro que pasa a reemplazar la unidad faltante por una cierta unidad ideológica o de intereses, según sean los grupos que sustenten tales iniciativas. De ese modo, asistimos hoy día al fenómeno de la formación de "universidades" masónicas, católicas de diversos tipos (respondiendo a los criterios de unidad proporcionados por diversas congregaciones), protestantes, de grupos de intereses económicos, políticos, sociales, etc. Las universidades estatales, en este esquema predominante impuesto por la época, comienzan a ser vistas como otras tantas organizaciones instaladas a partir de criterios dispersos. Rara vez se muestra de manera inequívoca, que la exigencia de tener un financiamiento estatal provenga de la necesidad de mantener una institución que responda adecuadamente a la esencia de la libertad científica, de la libertad de creación y de la enseñanza laica, en el sentido aquí señalado, es decir, organizada en vistas de mantenerse abierta a la unidad faltante.

Las universidades estatales, no es que deban ser financiadas por el Estado por la ya buena razón de que sin este aporte ellas no serían capaces de existir. Ellas son el Estado chileno en el ámbito del saber, de la ciencia y de la enseñanza profesional. Y el Estado debe ser sostén de ellas, porque sin su aporte no es posible que existan instituciones cuya finalidad sea dirigirse libremente hacia la unidad faltante del saber y de las ciencias. Un Estado que deja de cumplir este rol, abandona de hecho el desarrollo de estas disciplinas a los intereses ideológicos, económicos, políticos o de grupos, lo cual significa empujarlos a su decadencia y muerte. Las épocas más oscuras de la humanidad son aquellas en las que la ciencia, la filosofía y el arte han estado expuestos a las presiones de los intereses privados o de grupos. El Estado debe asumir la universidad como una de las condiciones de su supervivencia, en la medida en que es en ella donde debieran formarse los hombres de la universalidad, los verdaderos hombres de la nación, los que precisamente por ser universitarios sean capaces de vivir en el espíritu libertario que requiere el Estado para representar sin sectarismo a todos los ciudadanos. 


\section{ALGUNAS CONSIDERACIONES FINALES}

En la antigüedad griega, patria de origen de las disciplinas humanistas, fue determinante la conciencia de que todo saber humano es necesariamente limitado y que se encuentra siempre enmarcado en un no saber que le corresponde. Lo decisivo en la frase apolínea "conócete a ti mismo"-frase que podría aún constituirse en el lema de este tipo de estudios- es el llamado a recordar que el conocimiento a que el hombre puede aspirar a partir de sus propios medios es limitado, y que el intento de traspasar esos límites constituye una soberbia en la que se arraigan males como el fanatismo, la intolerancia, el absolutismo, el sectarismo, pero también otros, como la ambición desmedida, el ciego pragmatismo, la imprevisión y la imprudencia.

Esta delimitación del saber por el no saber es la apertura del hombre hacia el enigma que siempre lo rodea, y que la angustia y la desesperación por la condición humana a veces no quisieran reconocer. La pretensión de cerrar el círculo del saber humano, que debiera quedar siempre abierto, genera una falsa ilusión y aún una más falsa seguridad que también pueden traer graves consecuencias. La universidad tiene que ser la institución garante de esta apertura, en la que por eso mismo se asegura el amplio despliegue de todas las posibilidades humanas de imaginación y de conocimiento. En todas las disciplinas universitarias de un modo u otro se experimenta que el saber cómo pura positividad es hoy día imposible, incluso en el campo de las ciencias.

Frente a este hecho, es bueno recordar la forma en que el mundo griego enfrentó esta modalidad de experiencia humana, pues en gran medida la ausencia de una unidad del saber encarada como carencia proviene del desencanto que genera el derrumbe de la situación anterior, en la que la fe la aseguraba. Pero una desilusión como ésta tiene como condición de posibilidad de la ilusión anterior, que por obra del desarrollo mismo del saber se ha ido corroyendo. Si logramos ubicarnos en una perspectiva que se desplace mas allá de este desencanto, podemos fácilmente descubrir que eso que la desilusión muestra como puramente negativo, en realidad puede también ser positivo. Un límite no necesariamente es algo perjudicial y lamentable, también puede ser la forma en que se le aparece a la mirada humana su propia especificidad y su propia esencia. Frente a Dios o frente a los ángeles, el hombre aparece como un ser extraordinariamente limitado, pero esa comparación no es ni necesaria, ni deseable. El constatar nuestros límites es abrirnos a nuestra propia esencia para reconocerla y asumirla en su verdad. Así, lo negativo de la constatación de la imposibilidad de la unidad positiva del saber se transforma en algo 
positivo cuando logramos ser capaces de pensar que esa misma falta de unidad es precisamente la única forma legítima en la que el hombre puede ser capaz de acceder a una unidad. Esta unidad faltante del saber aparece entonces como la forma legítima de la unidad en una universidad que se piensa sin referencia a ilusiones.

El reconocimiento de la unidad faltante del saber es la conciencia de que para una universidad laica, lo verdaderamente decisivo no es el saber positivo que se administra e imparte a través de sus diferentes facultades, centros e institutos, sino el no saber, la apertura hacia el misterio, la docta ignorancia que siempre fue característica esencial y definitoria de las humanidades. "Solo sé que nada sé" pensó Sócrates. Las humanidades no se han constituido en sistemas de conocimientos compartidos universalmente porque contengan una debilidad en su origen, sino porque corresponden del modo más apropiado a la naturaleza misma del saber humano, que solo se legitima en la medida en que permanece abierto y en la medida en que él mismo sea un camino hacia la libertad. Las humanidades no son ciencias deficientes o incompletas, son disciplinas donde se ejerce la inteligencia y la imaginación humanas de manera original y siempre renovada, y que por eso mismo no deben medirse con la vara de disciplinas que no son como ellas. En su propia especificidad radica su fuerza, y una institución que pretenda desarrollarlas sin respetar sus particularidades está destinada a fracasar. Aunque en su interior se desarrollen diversas formas de investigación que pueden llegar a tener un carácter científico, la medida de las humanidades no puede ser la ciencia.

De ahí la necesidad de comprender cabalmente la importancia que éstas tienen y su rol particular en cuanto factores generadores de universalidad y de centralidad. Frente a centros de saber que todavía trabajan con el presupuesto de fondo de que la verdad es positivamente asequible, o que son indiferentes frente a este aspecto, el carácter abierto que poseen las humanidades constituye en verdad su fuerza, pues ello es testimonio de que ellas asumen en plenitud la esencia limitada del hombre y proyectan su quehacer sin intentar transgredir sus verdaderas posibilidades. Esa es la razón por la cual cualquier formalización de los estudios en este campo debe hacerse tomando como punto de partida la afirmación de que no se trata en ellas de disciplinas cerradas y completas, sino de intentos de respuesta siempre cuestionables y siempre conscientes de la unidad faltante, que es la esencia de la actual posición de universalidad.

De esto surge el que la unidad faltante y el saber del no saber exigen que las formas de evaluación y de calificación del trabajo académico sean hechas a partir de la especificidad de cada disciplina. Por otra parte, ellas deben 
mantenerse siempre abiertas a la creación de nuevas formas de discursos y procedimientos. Ello nos obliga a valorar en forma correcta tanto el conocimiento que es obra de un trabajo riguroso de investigación, como la creatividad que es producto del puro talento individual y que se mide por criterios que este mismo pone. Conocimiento y creatividad no son la misma cosa, pues en un caso estamos en una empresa colectiva que sigue de cerca las formalidades del trabajo científico, y en el otro estamos en un desafío individual, que depende del talento personal y que cada vez que se ejerce debe encontrar sus propias formas de rigor. Una verdadera política hacia las humanidades debe asumir en forma renovada el hecho de que la libertad de pensamiento y de creación, el fortalecimiento de la democracia, el respeto de los derechos humanos, la solidaridad y todas las grandes metas que configuran un verdadero horizonte histórico, dependen del desarrollo de los valores humanistas, y no únicamente de la consecución de un proceso unilateral de modernización. Pero, al mismo tiempo, debe afirmar la importancia de aspectos no directamente relevantes para el desarrollo social, político o económico de la sociedad, como el conocimiento de las lenguas clásicas, de las culturas antiguas y de las propias tradiciones humanistas. Asumir el desarrollo de las humanidades significa superar el pragmatismo de las políticas contingentes y elevarse hacia la posición de metas puramente universitarias en aras de ahondar en las raíces de nuestra cultura.

Los universitarios humanistas son los principales garantes del no saber y los más respetuosos de la unidad faltante, de donde surgen el resguardo del pluralismo, la autonomía con respecto a posiciones políticas, ideológicas o religiosas, y el respeto mutuo de los que trabajan en el área. La necesidad de afirmar la especificidad de las humanidades no nace de un cálculo de poder, ni por el deseo de defender mezquindades frente a otras mezquindades, sino por la convicción profunda de nuestra responsabilidad de educadores frente a las jóvenes generaciones que esperan recibir de nuestras manos la misma antorcha que nuestros maestros pusieron en las nuestras. 